by itself it affords no reasonable. ground for a diagnosis Numerous other signs and symptoms must be carefully weighed, perhaps at short intervals, before it is justifiable to express more than a provisional diagnosis.

\section{AN INVESTIGATION INTO THE ETIOLOGY OF ERYSIPELAS AND ALLIED INFECTIONS.}

By P. N. PANTON, M.A., M.B., B.C. Cantab., Clinical PaTHOLOGIST to THE LONDON hospitax; AND

J. E. ADAMS, M.B., B.S. LOND., F.R.C.S. ENG., LATE SURGICAL REGISTRAR AND RESIDENT ASSISTANT SURGEON TO ST. THOMAS'S HOSPITAL.

THE present investigation was undertaken with a view to determining certain disputed points in the etiology of erysipelas and the allied inflammatory lesions, cellulitis and lymphangitis. Erysipelas is commonly defined as a "specific and contagious infective disease due to the development of the streptococcus erysipelatis of Fehleisen in the smaller lymphatics of the skin." I It has for long been a matter of dispute as to whether or not the streptococcus erysipelatis should rank as a specific organism, and it appears now to be generally taught that this streptococcus is in all probability identical with the streptococcus pyogenes, but in order to account for certain discrepancies it is descrubed as "of a certain degree of virulence," ${ }^{2}$ yet the term streptococcus erysipelatis is still retained in the majority of descriptions of the disease. In addition to erysipelas proper a more extensive type of acute superficial inflammation is defined under the titles of "phlegmonous" and "cellulo-cutaneous erysipelas." In this variety certain clinical features are described by which it may be distinguished from erysipelas on the one hand and cellulitis on the other; it is stated to be doubtful whether or not it is contagious, ${ }^{3}$ and it has been suggested to be the product of a mixed streptococcal infection, "the erysipelas organism growing in the skin and. the streptococcus pyogenes in the deeper structures." + Two further conditions of acute superficial spreading inflammation with which erysipelas is liable to be confounded are those of cellulitis and of acute Iymphangitis in its later stages. While the specific nature of erysipelas is widely recognised, it is allowed that a spreading inflammation of the subcutaneous tissues-or cellulitis-which presents distinctive clinical features, may be produced by a variety of organisms, and that in some of the more localised forms the staphylococcus pyogenes aureus is the causative agent. ${ }^{5}$ Acute lymphangitis, in the same way, has no claim to be considered as a specific disease and neither this condition nor that of cellulitis is anywhere liable to " notification."

In considering the etiology of erysipelas it is necessary to determine the nature of the organism which causes the condition, and the relation which it bears, if any, to the organisms present in such allied inflammations as cellulitis and lymphangitis. Of recent years a considerable amount of work has been done upon the differentiation of the strepto. cocci and their classification. Andrewes and Horder ${ }^{6}$ have isolated a large number of streptococci from various sources and have been able to arrange them into a few fairly definite groups which depend for their differentiation mainly upon the reactions set up by the organisms in the carbohydrate media introduced by Gordon. The streptococci are thus found to fall into three main groups, representing three fairly constant varieties, which have been classed by Andrewes and Horder under the names of the strepto. coccus pyogenes, the streptococcus fæcalis, and the streptococcus salivarius, with its closely allied variant the streptococcus anginosus. In the same manner the pneumococci, while presenting many points of similarity with the streptococci, are found to form a distinctive group, possessing fairly constant reactions. In this investigation an attempt has been made to isolate the causative organism from cases of erysipelas, and of the

I Rose and Carless - Manual of Surgery, 1902, p. 94.

Muir and Ritchie : Manual of Bacteriology, 1902, p. 182 Rose and Carless: Manual of Surgery, 1902, p. 96. 4 Cheyne and Burghard: Manual of Surgical Treatment, 1904, Part i., p. 217

5 Rose and Carless : Manual of Surgery, 1902, p. 80

${ }^{6}$ Andrewes and Horder: THE LANCET, Sept. 15th, 1906, p. 708. similar acute spreading inflammations of the skin and subcutaneous tissues, and to subject them to all possible cultural tests, including Gordon's carbohydrate media, with the object of determining whether the causative organism of erysipelas is a constant one, and whether it presents any features by which it may be distinguished from the other pyogenic streptococci.

These questions are of some practical importance since the various surgical procedures which have been adopted in cases of erysipelas appear to have no recognisable influence in shortening the course of the disease and of recent years treatment by serum-therapy has been largely employed. The serum used has been derived from various sources. The so-called anti-erysipelas serum is usually derived from the serum of a horse which has been inoculated with a mixed culture of streptococci obtained from several cases of erysipelas; sometimes a streptococcus pyogenes serum is used, the horse in this case having been immunised by a pure culture of one or more strains of the streptococcus pyogenes ; a "polyvalent" streptococcal serum is also employed and is obtained from various strains of streptococci chosen indiscriminately from different lesions. Uncertain as is the value of serum-therapy in erysipelas, it would obviously be of importance to ascertain if all cases of erysipelas are due to the same organism before drawing any conclusions as to the value of serum treatment in any particular series of cases.

In addition to the bacteriology of these infections certain points in their histology have been investigated when the necessary material has been available. The various cases were taken from the wards and out-patient department of St. Thomas's Hospital, and in each instance the source and mode of infection were investigated so far as it was possible. A review of all cases of erysipelas admitted to, or arising in, the hospital over a period of 12 years was also made in order to determine if cases of erysipelas, by spread of infection, gave rise to this disease only, and, conversely, if other septic conditions ever gave rise to erysipelas. The answer to these questions, upon which the specific character of erysipelas depends, determines the manner of dealing with these cases. Should erysipelas patients alone be isolated, or should all cases of streptococcus infections be placed together?

Technique.-In the erysipelas cases films were made and cultures taken from the exudation of the wound when this was available. The films were stained by Gram's method and the culture media employed were "lemco" broth and nasgar. In cases of mixed infection an isolated streptococcus colony was, when possible, inoculated on to a second nasgar tube and the subsequent growth transferred to the various media; isolation by plating on Petri dishes was usually avoided, since the colonies thus obtained frequently died out on being transferred to liquid media. The behaviour of the streptococci thus obtained upon agar and gelatin, in litmus milk, broth, neutral red broth under anaerobic conditions, and a large number of Gordon's carbohydrate media, was in each case fully investigated. In a certain number of instances, however, owing to the presence of other actively growing organisms, the nature of the streptococcus present could not be determined. In a number of cases in which blebs of considerable size were present, these were opened aseptically and several loopfuls of their contents smeared over a nasgar slope. In a few cases in which neither a discharging wound nor blebs were present the skin at the spreading edge of the rash was scarified with a sterile needle and cultures taken from the exuding serum. In some instances films made from the bleb contents or from the clear serum obtained on scarifying the skin were treated by Leishman's stain and a differential count was made of the cells present. In only one or two cases could portions of the skin be obtained for histological purposes. In the cellulitis and lymphangitis cases films and cultures were investigated in a similar way, and were obtained either from the original wound or from the pus evacuated at the time of operation. In several of the cellulitis cases small portions of the skin were removed during the operation for microscopy. In all about 60 cases were investigated, the majority of which were diagnosed as erysipelas; a few cases in which an operation was followed by a spreading erythema of doubtful nature are also included.

The erysipelas infections.-Out of 60 cases examined bacteriologically 38 were considered on clinical grounds to be typical instances of erysipelas. The following is a short 


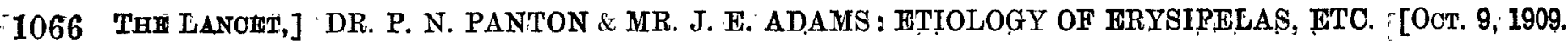

account of a few of such cases as illustrate points of importance in the etiology of the disease.

CASE 2.-A skin graft was taken from the chest for a plastic operation on the fingers. 24 hours later erysipelas developed about the raw surface on the chest; the skin graft also suppurated freely, but did not give rise to erysipelas. A scarification of the skin at the spreading edge of the rash produced a sarcina only. The pus from the raw surface on the chest yielded a pure growth of a streptococcus. This coccus was in every respect a typical streptococcus pyogenes, and was apparently inoculated by the surgeon into the superficial layers of the slsin, producing erysipelas, and into the subcutaneous tissues of the fingers, producing suppuration only.

CASE 22,-Osteomyelitis of the radius in a child was operated on and erysipelas arose round the wound seven days later. An abscess of the neck was opened three days before the onset of the erysipelas. Cultures from the bone abscess gave staphylococcus aureus, a diphtheroid bacillus, and a typical streptococcus pyogenes; from the neck abscess staphylococcus aureus, staphylococcus albus, and a typical streptococcus pyogenes were grown. In this case the aureus was no doubt the cause of the osteomyelitis and of the neck absess. The streptococcus was introduced later into the arm and the neck, giving rise to erysipelas in the one place but not in the other.

CASE 26.-An abscess of the neck was opened and erysipelas developed some days later. Cultures from the bleb and from the abscess yielded a growth of staphylococcus albus and a typical streptococcus pyogenes. This was the only instance in which a streptococcus the abscess was supposed to have been caused by the albus and the streptococcus to have been introduced in a subsequent dressing.

CASE 28. - An appendix abscess was opened and some weeks later CASE 28. - An appendix abscess was opened and some weeks later
erysipelas developed around the still discharging sinus. Cultures from erysipelas developed around the still discharging sinus. Cultures from the sinus gave a growth of staphylococcus albus and a fairly typical
streptococcus fæcalis. It is possible that in this case the streptococcus streptococcus fæcalis. It is possible that in this

CASE 29.-A breaking-down carcinomatous gland of the neck was opened, and the wound was afterwards plugged in order to check secondary hæmorrhage; within 24 hours erysipelas developed. Cultures from the neck produced a diphtheroid bacillus and a typical pneumococcus. This coccus was inoculated subcutaneously into a mouse which died four days later. Capsulated diplococci were present in the hear blood, and a pure culture of the pneumococcus obtained from the spleen. The breaking-down growth in the neck communicated with the buccal cavity, and it is possible that the pneumococcus causing the erysipelas was derived from the mouth and inoculated on to a raw surface at the time of the operation. The patient died, and a portion of the skin at the edge of the wound was removed at the post-mortem examination, and sections showed necrosis and cedema of the epithelium, a marked cellular exudation around the blood-vessels, together with numerous bacilli and a few Gram-positive diplococci.

CASE 49.--Cellulo-cutaneous erysipelas following a contusion of the elbow of three weeks' standing. The fluid from a bleb contained large numbers of polynuclear cells. Cultures from a bleb grew the staphynumbers of polynuclear cells. Cultures from a bleb grew the staphyculture of a somewhat unusual streptococcus approaching in type to the pneumococcus, but which we have classed as a streptococcus pyogenes. A portion of skin was removed at the operation and sections of this show clearly a typical acute inflammatory condition of the epidermis itself ; the superficial layers of the epidermis are in places stripped up, itself ; the superticial layers of the epidermis are in places stripped up, cells. These sections are markedly different from those derived from the cells. These sections are markedly different from those
cases of acute cellulitis, unaccompanied by erysipelas.

cases of acute cellulitis, unaccompanied by erysipelas.
CASE 53.-A double osteotomy of the femora for rachitic curvatures CASE 53.- A double osteotomy of the femora for rachitic curvature
was followed in three days by suppuration of both legs. The suppurawas followed in three days by suppuration of both legs. The suppura-
tion continued for some weeks, and erysipelas eventually supervened tion continued for some weeks, and erysipelas eventually supervened around the sinus in the left leg, the condition of the right leg remaining unaltered: Three days after the commencement of the erysipelas cultures were taken from the left leg and produced a staphylococcus aureus and a streptococcus. The following day cultures were taken also from the right leg and staphylococcus aureus and a streptococcus were again grown; about 24 hours later a typical attack of erysipelas arose around the sinus of the right leg. The streptococci derived rom litm legs were in every not affect salicin, we have classified them as members of the streptococcus pyogenes group, since in every other respect they more closely resemble pyogenes than fæcalis, This case is of particular interest in that it illustrates the fact that a streptococcus may give rise to erysipelas in one part of the body during the course of another attack of erysipelas due to the same organism in course limb. another thas coccus was demonst erysipelas, in the einus for any in the sinus for any length of time. The staphylococcus aureus was a purulent condition of the scalp. Anti-erysipelas serum was given subcutaneously wall, and was followed by a sloughing condition of th skin at the site of injection, and, later, by a typical erysipelas spreading from the point of inoculation. Cultures from the absess yielded staphylococcus aureus, staphylococcus albus, and a typical streptococcus pyogenes. This case resembles Case 53 in that tho separate attacks of erysipelas arose in different parts of the body daring the same period. The serum used in this case seems to have been quite functionless, even though given, as it was, before the onse $t$ of the second attack. The mixed infection was possibly transferred by the patient from her scalp to the puncture wound of the hypodermic nsedle.

CASE 57.-A wound in the neck of a child was followed by facial erysipelas. Cultures from the wound yielded staphylococcus albus and streptococcus pyogenes. A culture from the streptococcus isolated was inoculated into two mice; in one case into the cellular tissues beneath the skin, in the other case into the scarified epidermis itself. The mouse inoculated subcutaneously died in three days, and numerous streptococi were found to be present in films taken from the heart blood. Sections taken at the site of inoculation showed acute inflammation of the subepidermal cellular tissues, the epidermis itself being normal. The second mouse remained well and was killed four days after inoculation; nothing could be seen at the site of the scarified skin and nothing abnormal was found in the sections of the epidermis in this situation; no organisms were found in the films of the heart blond.

The following tables (Tables I. and Ir.) give the full cultural characters of the streptococci isolated in the erysipelas cases :-

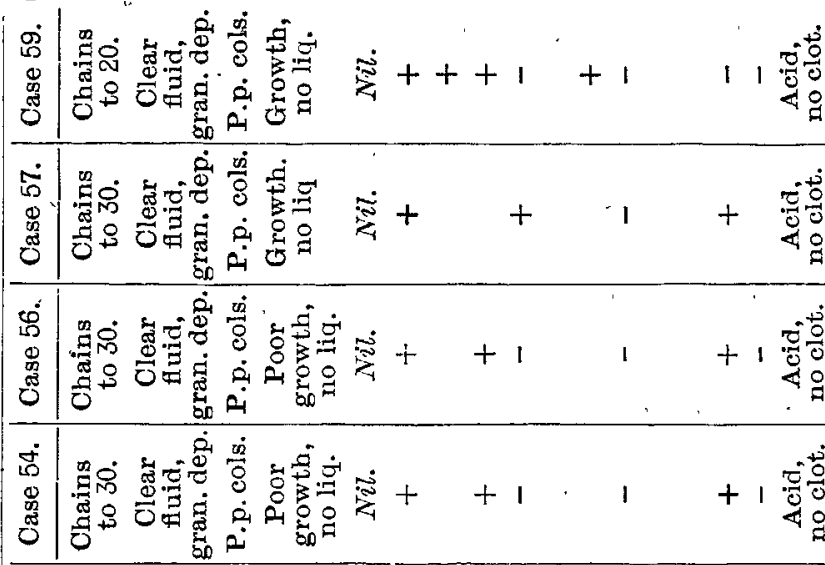

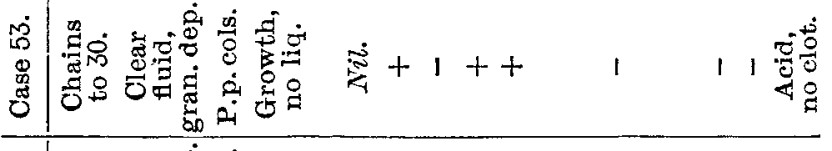

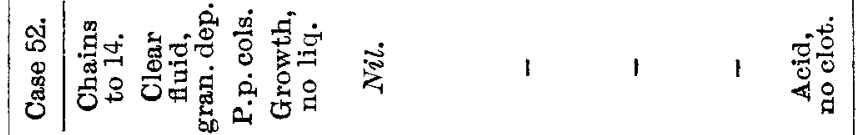

\begin{tabular}{|c|c|c|c|c|c|c|}
\hline 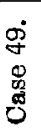 & 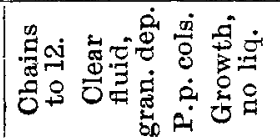 & $\underset{\pi}{\frac{\pi}{4}}+$ & +1 & + & 1 & 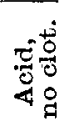 \\
\hline 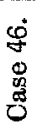 & 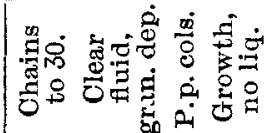 & $\overrightarrow{\vec{z}}+$ & +1 & 1 & $i$ & 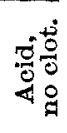 \\
\hline
\end{tabular}

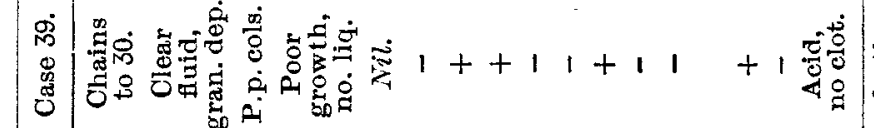

官 券 过

告

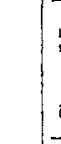

0
$\dot{3}$
0
0
0
0
0 i

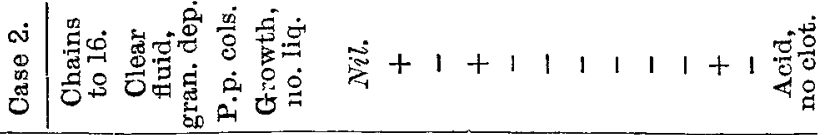

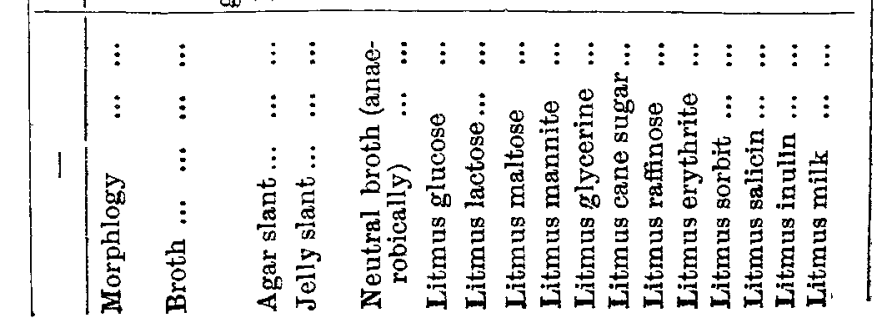


THE LANCET,] DR. P. N. PANTON \& MR. J. E. ADAMS : ETIOLOGY OF RRYSIPELLAS, ETC. [OOT. 9, 1909.1067

TABLE II.-Erysipelas Cases; Streptooooous Frecaiis Group.

\begin{tabular}{|c|c|c|c|c|}
\hline 一 & Case 20. & Case 28. & Case 30. & Case 51. \\
\hline Norphology... ... & $\begin{array}{c}\text { Chains to } \\
8+\end{array}$ & $\begin{array}{c}\text { Chains to } \\
30+\end{array}$ & $\begin{array}{c}\text { Chains to } \\
90\end{array}$ & $\begin{array}{l}\text { Long } \\
\text { chains. }\end{array}$ \\
\hline Broth $\ldots \quad \ldots \quad \ldots$ & $\begin{array}{l}\text { Clear fluid, } \\
\text { gran. dep. }\end{array}$ & $\begin{array}{l}\text { Clear fluid, } \\
\text { gran. dep. }\end{array}$ & $\begin{array}{l}\text { Clear fluid, } \\
\text { gran. dep. }\end{array}$ & $\begin{array}{l}\text { General } \\
\text { turbidity, } \\
\text { gran. dep. }\end{array}$ \\
\hline Agar slant $\ldots . .$. & P.p. cols. & P.p. cols. & P.p. cols. & P.p. cols. \\
\hline Jelly slant $\ldots \quad \ldots$ & $\begin{array}{l}\text { Very poor } \\
\text { growth, } \\
\text { no liq. }\end{array}$ & $\begin{array}{l}\text { Very poor } \\
\text { growth, } \\
\text { no liq. }\end{array}$ & $\begin{array}{l}\text { Very poor } \\
\text { growth, } \\
\text { no liq. }\end{array}$ & $\begin{array}{c}\text { No } \\
\text { growth. }\end{array}$ \\
\hline $\begin{array}{l}\text { Neutral red broth } \\
\text { (anaerobically) }\end{array}$ & $N u l$ & Nil. & $\begin{array}{l}\text { Abundant } \\
\text { growth, } \\
\text { no altera- } \\
\text { tion of. }\end{array}$ & Nil. \\
\hline Litmus glucose ... & + & + & + & + \\
\hline Litmus lactose ... & + & + & + & - \\
\hline Litmus maltose ... & + & + & + & + \\
\hline Litmus mannite & + & + & + & + \\
\hline Litmus glycerine & + & - & - & - \\
\hline Litmus cane sugar & + & + & + & - \\
\hline Litmus raffinose... & - & + & . & - \\
\hline Litmus erythrite & + & - & - & - \\
\hline Litmus sorbit $\quad \ldots$ & - & ". & $\therefore$ & \\
\hline Litmus salicin ... & + & + & + & - \\
\hline Litmus inulin $\ldots$ & - & - & - & - \\
\hline Litmus milk & $\begin{array}{c}\text { Acid, } \\
\text { no clot. }\end{array}$ & $\underset{\text { investigated. }}{\text { Not }}$ & $\begin{array}{c}\text { Acid, } \\
\text { no clot. }\end{array}$ & $\begin{array}{c}\text { Acid, } \\
\text { no clot. }\end{array}$ \\
\hline
\end{tabular}

Gran. dep. = granular deposit; p.p. cols. = 'pin-point colonies; n liq. $=$ no liquefaction; $+=$ acidified; and $-=$ no acid production.

The preimococcus obtained from Case 29 gave the following cultural reactions:-Broth, general turbidity and granular deposit; agar, pin-point colonies; jelly slant, no growth; nentral red broth (anaerobically), green fluorescence litmus.glucose, acid ; litmus lactose, acid; litmus maltose, acid; litmus mannite, nil; litmus glycerine, nil; litmus cane sugar, acid; litmus raffinose, acid; litmus erythrite, nil; litmus salicin, nil; litmus milk, acid and solid clot. In addition, a mouse was inoculated subcutaneously and died four days later. Capsulated diplococci were present in smears from the heart blood and a pure culture of the pneumococcus was obtained from the spleen.

Out of these 38 cases of erysipelas an organism of the streptococcus class was found to be present in 29 instances. In only one case, in which a wound was present, was no evidence of a streptococcus obtained either in the films or in cultures made from the wound; diplococci only were present in the films, and cultures yielded a: profuse growth of the staphylococcus aureus. We regard this exception as due to a technical error and consider that a streptococcus was probably present but was not demonstrated owing to the abundant growth of the staphylococcus. In the remaining eight cases to wound was present, and it was only possible to obtain cultures either from a bleb or from the fluid obtained on scarifying the skin, and both of these appear to be most unfarourable materials for demonstrating the causative organism. That the abundant inflammatory exudate, usually present in the blebs, should so rarely produce a growth of the streptococcus was a somewhat unexpected occurrence, and on only one occasion was such a growth obtained; the explanation may be that these localised collections of serum possess bactericidal properties. In the 30 cases, therefore, in which a wound was present an organism of the streptococcus class was found on 29 occasions. Of these 29 strains six could not be isolated owing to the presence of other organisms. In 23 cases the full cultural characters of the organisms were obtained, and these have been grouped according to the classification of Andrewes and Horder--that is to say, 18 have been classed as members of the streptococcus pyogenes group, four as examples of the strepto. coccus fæcalis, and one as a pneumococcus. While it would, perhaps, be unwise to accept the classification of Andrewes and Horder as final, and to regard the streptococci which they have differentiated as true species, yet sufficient evidence is afforded that the various strains of streptococci can, on the basis of their cultural reactions, be divided into a few fairly definite groups, and that any member of each of these groups is capable of retaining its special cultural reactions for many generations either outside the body or after its passage through animals. If, then, the streptococcus erysipelatis possessed any peculiar and established pathogenic properties, and if that streptococcus produced only erysipelas, we should expect to find that it possessed al:o peculiar and established cultural reactions. There is, however, we think, sufficient evidence that while the typical streptococcus pyogenes is the coccus most frequently met with in erysipelas, yet streptococci, which exhibit considerable cultural differences, and even pneumococci, are in a fair percentage of cases the causative organisms. Moreover, the variability of the organisms met with in erysipelas appears, as will be seen, to be closely comparable with that of the organisms present in cellulitis, a condition which has never enjoyed the distinction of being considered a specific disease. It has, however, been urged in favour of the specific character of erysipelas that the disease is transferred as such from one patient to another; yet while this undoubtedly does occur, as, indeed, one would expect, such evidence as we have been able to obtain shows it to be an event of considerable rarity. The subjoined tables (Tables III. and IV.) have been drawn up from the published hospital statistics concerning the incidence of erysipelas cases arising during the stay of patients in St. Thomas's Hospital. Only those instances of erysipelas arising round a prexisting, wound have been considered, as in these casess only were the statistics showing the incidence of erysipelas in surgical wards reliable. The inclusion of other cases, such as, those of facial erysipelas, would, as a matter of fact, have made little difference in the statistical relationship between. the number of beds and the number of instances of the disease in question. The average number of surgical beds was 264 and was distributed as follows : 240 in the general wards, and 24 in the septic wards. From 1896 to 1905 no attempt was made to isolate erysipelas cases from other cases admitted to the septic wards, but in 1906 six additional beds, in small isolation wards in the septic block, were added for the accommodation of erysipelas cases. This year is omitted from both tables since the arrangement was

TABLE III.-Showing Incidenoe of Erysipelas around Wounds arising in Hospital.

\begin{tabular}{|c|c|c|c|}
\hline Year. & $\begin{array}{l}\text { Number of } \\
\text { cases. }\end{array}$ & $\begin{array}{l}\text { In septic } \\
\text { wards. }\end{array}$ & $\begin{array}{c}\text { In general } \\
\text { surgical wards. }\end{array}$ \\
\hline $\begin{array}{lll}1896 & \ldots & \ldots\end{array}$ & 18 & 2 & 16. \\
\hline $1897 \quad \ldots \quad \ldots$ & 17 & 1 & 16 \\
\hline $1898 \quad \ldots \quad \ldots$ & 18 & $\because 4$ & 14 \\
\hline $1899 \quad \ldots \quad \ldots$ & 12 & $\therefore \quad 2$ & $\cdots 10$ \\
\hline $.1900 \quad \ldots \quad \ldots$ & 19 & 3 & 16 \\
\hline $\begin{array}{lll}1901 & \ldots & \ldots\end{array}$ & 7 & 2 & 5 \\
\hline $1902 \ldots \ldots$ & 18 & 3 & 15 \\
\hline $1903 \ldots \ldots$ & 27 & 8 & 19 \\
\hline$\cdot 1904 \quad \ldots \quad \ldots$ & 19 & 4 &, .15 \\
\hline $1905 \quad \ldots \quad \ldots$ & 21 & 5 & 16 \\
\hline $\begin{array}{r}\text { Total for ten } \\
\text { years ... } \ldots\end{array}$ & 176 & 34 & 142 \\
\hline Percentage ... & - & $19 \cdot 31$ & $80 \cdot 69$ \\
\hline
\end{tabular}

Note--Proportion of children under six to adults is about the same in general and septic wards.

TABLE IV.-Shoning Incidence of Erysipelas around Wounds arising in Hospital after Isolation Wards nere established for Erysipelas Cases.

\begin{tabular}{|c|c|c|c|}
\hline Year. & $\begin{array}{l}\text { Number of } \\
\text { cases. }\end{array}$ & $\begin{array}{l}\text { In septic } \\
\text { wards. }\end{array}$ & $\begin{array}{c}\text { In general } \\
\text { surgical wards. }\end{array}$ \\
\hline $1907 \quad \ldots \quad \ldots$ & 18 & 5 & 10 \\
\hline $1908 \quad \ldots \quad \ldots$ & 13 & 7 & 6 \\
\hline Total $\quad \ldots \quad \ldots$ & 31 & 15 & 16 \\
\hline Percentage ... & - & $48 \cdot 4$ & $51 \cdot 6$ \\
\hline
\end{tabular}


made in the middle of 1906 . In 1907 and 1908 we have the figures for a short period during which the erysipelas cases were isolated. A comparison of these two tables shows clearly that while the incidence of erysipelas is, as one would expect, greater in septic wards than in the general surgical wards, yet the separation of erysipelas from other septic cases has had no effect in lessening the occurrence of erysipelas in these septic wards.

The figures for the occurrence of erysipelas in the septic wards for 1908 include three cases which arose under the following circumstances. The erysipelas isolation wards being full, a girl with a sinus of buttock surrounded by a septic eczema was admitted to the female septic ward on Dec. 9th. On the following day, with no constitutional disturbance, there was an added, somewhat marginated, erythema over the buttock. This redness lasted only for 24 hours and did not spread beyond the buttock. The patient remained in the ward. On Dec. 18th two cases in the same ward, one with a wound due to necrosis of the jaw, and the other with a discharging retro-pharyngeal abscess, developed erysipelas around their wounds; they were transferred to the erysipelas ward. Subsequently a culture was taken from the sinus of buttock and this yielded a growth of a streptococcus, and the case was then regarded as having been one of erysipelas of a fleeting nature or an instance of a "septic rash." There was at the same time a case of facial erysipelas in one of the two male septic wards because the male erysipelas ward was full, and in this ward no other cases of erysipelas arose. These two parallel cases go to prove that the danger of transmitted infection depends on the presence of discharge from a streptococcal wound rather than upon the risk of contagion from such a lesion as facial erysipelas, which is practically free from discharge. In this connexion it may also be noted that one or two cases of doubtful erythema were admitted direct to the special erysipelas ward, and the subsequent course of these cases proved that they were not suffering from erysipelas on admission, nor did they contract it, though exposed to infection, at any rate by aerial contagion.

With regard to the dressing of wounds in general, we may state that, as a rule, the dressing used was plain sterilised

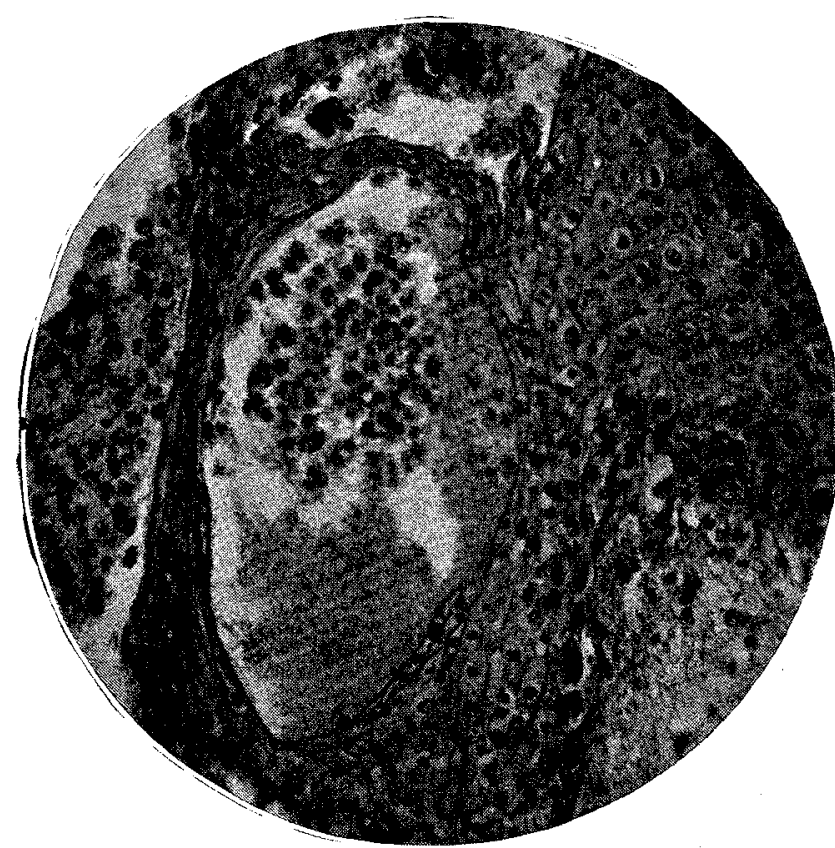

Microphotograph (No. 2 eyepiece, $\frac{1}{6}$ th inch objective). Section through centre of erysipelas "bleb" showing the collections of polynuclear leucocytes on the surface and within the layers of the epidermis. There is no cellular infiltration of the deeper structures. and the ear of a rabbit be carefully inoculated with a small quantity of a pure culture, local erysipelas usually resultsif, however, the streptococcus be highly virulent, the rabbit dies of general septicæmia." 8 That the varying lesions usually obtained by inoculating animals with streptococci from various sources do not necessarily depend upon the degree of virulence of the organism in each case is shown by the experiment referred to above, in which a mouse died from septicæmia with spreading cellulitis after the inoculation of a streptococcus into its subcutaneous tissues, whilst another mouse simultaneously inoculated by means of rubbing in a culture of the same streptococcus into the scarified skin escaped unharmed; the different effect in this case might reasonably be explained solely by the difference in the point of entry of the organism.

Erysipelas is commonly considered to be more infections than cellulitis, and this may be due to the more superficial nature of the inflammation and to the desquamation which accompanies the former condition, but the danger of infection is the danger of transferring streptococci from one patient to another, a sufficiently seriuus event, of which perhaps the least serious effect is the production of erysipelas.

With regard to the mode of infection in these 38 cases of erysipelas, in 21 infection occurred outside the hospital, and in no instance was any history of exposure to infection obtained ; in many of the cases of facial erysipelas no obvious wound was present at the time of admission to the hospital, but some slight abrasion of the surface epithelium had doubtless taken place and subsequently healed. In 13 of these 21 cases in which streptococci were proved to be present other organisms were present in six cases, a streptococcus alone in seven cases. of the 17 cases of erysipelas arising in the hospital, one was infected at an operation and yielded a pure culture of a streptococcus. In the remaining 16 cases streptococci were found to be present in 15,13 times in company with other organisms, and twice only in pure culture. Many of these cases were infected with other pyogenic organisms at the time of operation and when suppuration commenced were in some instances transferred to a " septic" ward, which is now isolated from the gauze, though in some of the dirtier cases the gauze was wrung out in 1 in 40 carbolic before being applied to the wound.

There is direct evidence that the same organism may produce at the one time erysipelas and at the other cellulitis, an experiment which was accidentally performed in one case in this series in which a streptococcus was intrcduced into two separate lesions, giving rise to local suppuration in one place and typical erysipelas in the other. In two other cases, however, the transference of the streptococcus from one erysipelas infection to another lesion in the same patient was followed by a second attack of erysipelas, an event which may be explained by the supposition that the point of entry of the organism was in each case the epidermis. The evidence of animal inoculation is certainly opposed to the view that the organisms of erysipelas possess any specific properties. The animal experiments performed in this investigation are not sufficiently numerous or definite to admit of any conclusions being drawn from them; in one instance, however, the organism isolated from a case of erysipelas produced cellulitis, septicæmia, and death in a mouse, but no erysipelas. McFarland states that: "When injected into animals Fehleisen's coccus behaves exactly like streptococcus pyogenes," 7 and in another place, "If the cultures (of streptococcus pyogenes) be of moderate virulence erysipelas ward and nursed by a different staff. The preponderance of mixed infections in the hospital cases in cases arising outside the hospital is evidence of the com. parative failure of aseptic precautions when dealing with a large number of various infections. The one hospital case in which no streptococcus was found was a case of facial erysipelas, without obvious lesion, arising in a female was obtained in several instances in this series, and the extremely short period of immunity conferred by an attack was well shown in the cases of the two patients, in whom two separate outbreaks of erysipelas developed within a few days of the original attacks. It is worthy of note that while such streptococcal and pneumococcal infections as erysipelas, lobar pneumonia, and probably rheumatic fever are accompanied by but a brief period of immunity, and, indeed, actually predispose the patient to a second attack, yet scarlet fever, which is by some considered to be a streptococcal infection, frequently confers upon the patient a complete and life-long immunity.

A further point in the etiology of erysipelas, which was particularly investigated in this series, was the exact site of the inflammatory processes, and it would seem that in this consists the main, if not the only, difference between this contrast to the high percentage of pure infections in those medical ward. A history of a previous attack of erysipelas 
condition and that of cellulitis. Owing to the fact that in but it is improbable, at any rate in the cases in which the the great majoriiy of cases no indication for surgical incision rash becomes generalised and resembles the eruption of arose, in only two instances could portions of the skin be obtained for microscopy, and in both of these the epidermis itself showed the histological characters typical of acute inflammation. Many cases, however, were accompanied by th the formation of vesicles within the layers of the epidermis, and the cytological evidence of the fluid obtained from these pielded abundant evidence of the superficial site of the acute inflammation, the cells of the fluid in every instance consisting almost entirely of microphages and macrophages. In addition, in some cases in which blebs were absent similar cytological findings were obtained on scarifying the epidermis. The evidence that in erysipelas the condition is one of acute inflammation of the epidermis itself is in striking contrast to the histology of cellulitis, for although a clinical examination of the skin in cellulitis would appear to reveal scarlet fever, that the epidermis itself shares in the acute inflammation. The redness of the skin is probably due to a cutaneous dilation of the blood-vessels such as is present in the erythema of scarlet fever. Owing to the presence of other organisms the streptococcus could only be isolated in one of these cases; its cultural characters were as follows : Morphology, chains to 30 ; broth, clear fluid, granular deposit ; agar, pin-point colonies ; jelly, no growth ; neutral red broth (anaerobically), abundant growth, no alteration of colour ; litmus maltose, acid; litmus mannite, nil; litmus raffinose, acid; litmus salicin, nil; and litmus milk, acid, no clot.

Cellulitis cases. - Twelve of these cases were investigated altogether. They were chosen as typical cases of undoubted cellulitis and showed no clinical features of interest. The all the characters of an acute inflammation, yet examination full cultural characters of the cocci isolated are given in the

TaBLE V.-Cellulitis Cases; Streptococous Pyogenes Group.

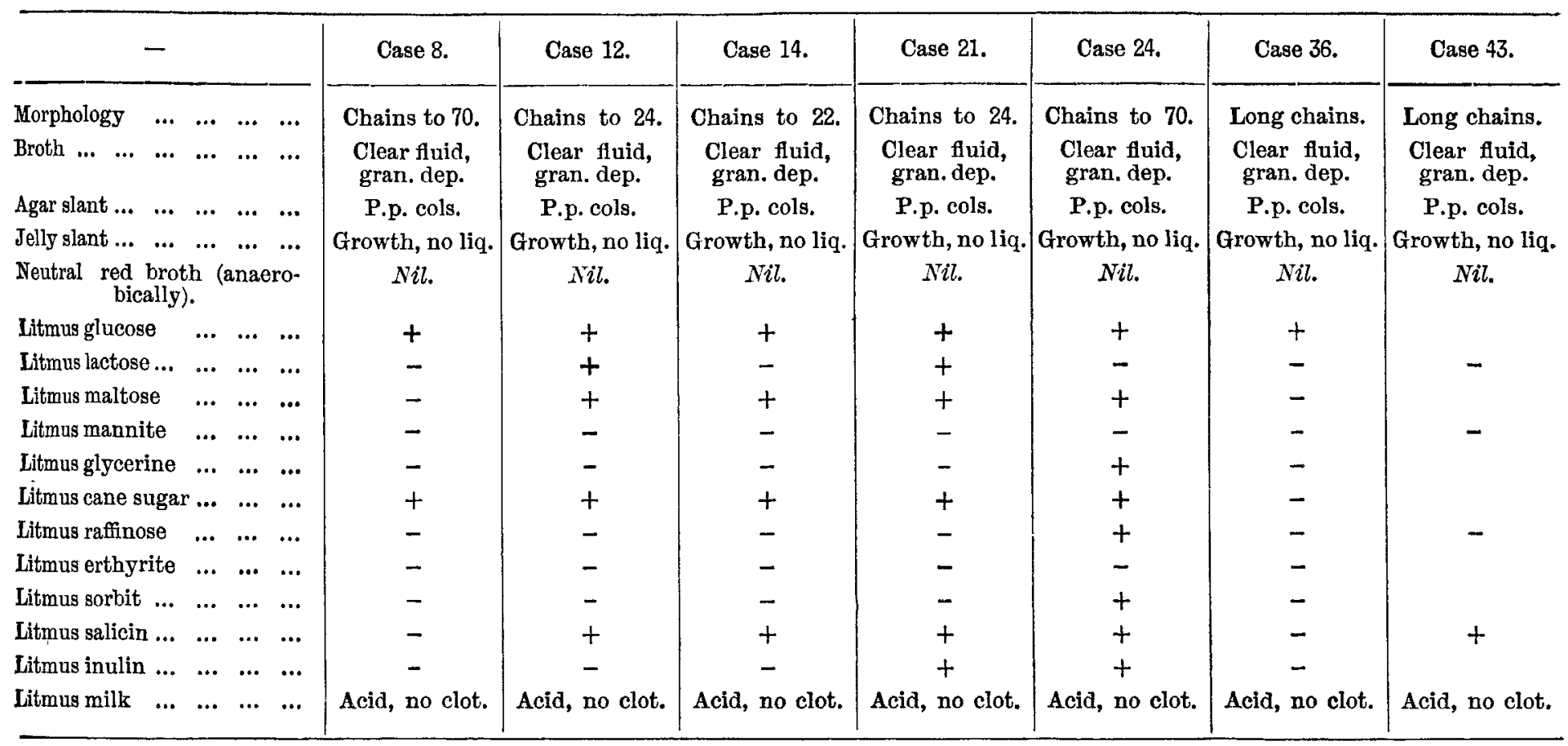

Gran. dep. = granular deposit ; p.p. cols. = pin-point colonies ; no liq. = no liquefaction ; $+=$ acidified ; and $-=$ no acid production.

of sections of the epidermis in this condition presents no evidence of any departure from the normal.

The treatment of erysipelas is somewhat outside the scope of this paper, but it may be mentioned that many of the cases were treated by some form of serum, and, on the whole, with very little effect, a result which may be in part explained by the probability that in many instances the serum employed was obtained by the immunisation of a horse with a streptococcus of different nature from the organism producing the erysipelas. In the only case in this series in which a chronic suppurative condition followed the acute attack of erysipelas, treatment by a vaccine prepared from the streptococcus obtained from the patient's tissues was promptly followed by marked improvement.

Cases of erythema of doubtful nature.-These cases, five in number, consisted of erythemata arising in connexion with septic wounds. In three instances the rash was generalised and the diagnosis of "surgical " scarlet fever was made. The first of these cases is included only as a control to the findings in the erysipelas cases. There was an erythema of the face without any constitutional symptoms. The serum obtained from an almost healed cutaneous wound in the erythematous area yielded no evidence of inflammation, nor was any pathogenic organism obtained from cultures taken from the fluid. In the remaining four cases an organism of the streptococcus class was obtained on three occasions, and a staphylococcus aureus in one case. In no case could a section of the skin be obtained, nor were any blebs present, and it is uncertain whether there was inflammation of the skin itself or not. It seems possible, however, that many of these "septic" rashes spreading from an infected wound are of an acute inflammatory nature and associated with organisms of the streptococcus class, accompanying tables (Tables V., VI., and VII.), and the organisms are grouped in the same manner as in the erysipelas cases.

TABLE VI.-Cellulitis Cases; Streptococous Facalis.

\begin{tabular}{|c|c|c|}
\hline - & Case 3. & Case 11. \\
\hline $\begin{array}{l}\text { Morphology. } \\
\text { Broth. } \\
\text { Agar. } \\
\text { Jelly. }\end{array}$ & $\begin{array}{l}\text { Chains to } 8 . \\
\text { Olear fluid, gran. dep. } \\
\text { P.p. cols. } \\
\text { Faint growth, no liq. }\end{array}$ & $\begin{array}{l}\text { Chains to } 22 . \\
\text { Clear fluid, gran. dep. } \\
\text { P.p. cols. } \\
\text { Very faint growth, } \\
\text { no liq. }\end{array}$ \\
\hline $\begin{array}{l}\text { Neutral red broth } \\
\text { (anaerobically). }\end{array}$ & Nil. & Nil. \\
\hline Litmus glucose. & Acid. & Acid. \\
\hline Litmus lactose. & Nil. & Acid. \\
\hline Litmus maltose. & Acid. & Nil. \\
\hline Litmus mannite. & Acid, & Nil. \\
\hline Litmus glycerine. & Nil. & Nil. \\
\hline Litmus cane sugar. & Acid. & Acid. \\
\hline Litmus raffinose. & Nil. & Nil. \\
\hline Litmus erythrite. & Nil. & $N i l$. \\
\hline Litmus sorbit. & Nil. & Nil. \\
\hline Litmus salicin. & Nil. & Nil. \\
\hline Litmus inulin. & Nil. & Nil. \\
\hline Litmus milk. & Acid, no clot. & $\begin{array}{l}\text { Acid + solid clot } \\
\text { (3 occasions). }\end{array}$ \\
\hline
\end{tabular}

In 12 cases of acute cellulitis a streptococcus was found to be present on 10 occasions, once an unusual coccus was 
TABLE VII. - Ceilulitis Cases; Unolassified Coecus.

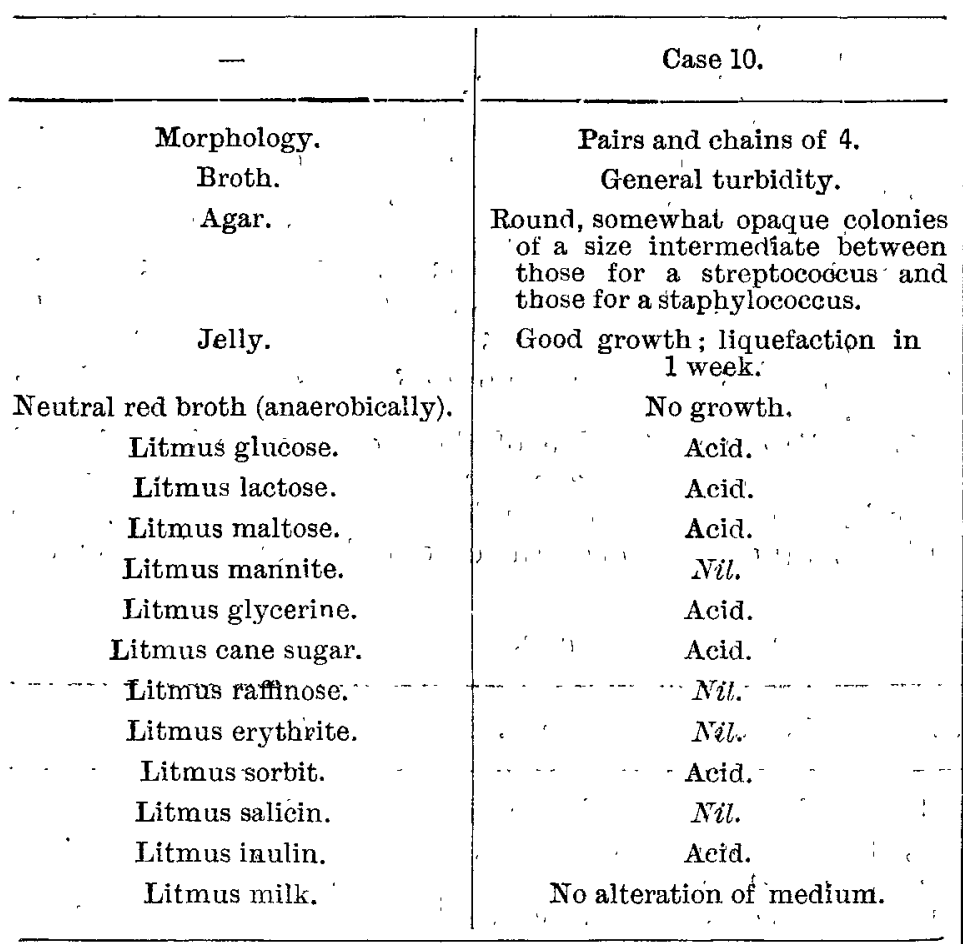

This coccus proved non-pathogenic to a guinea-pig.

obtained, and once a staphylococcus aureus. In the case in which staphylococci only were present no incision was made and the cultures were taken only from a varicose ulcer which was the starting point of the cellulitis. In the 11 cases in which organisms of the streptococcus class were present the coccus was not isolated on one occasion owing to an air contamination ; of the other 10 cases seven proved to be due to the streptococcus pyogenes, two to a streptococcus fæcalis, and one to an unclassified coccus. The cultural characters of the strains of streptococci obtained showed no typical variations by which they could be distinguished from the strains obtained in the erysipelas cases. Owing to the fact that an incision was necessary in the majority of cases, the streptococcus was frequently found in pure culture, and it was possible to obtain small portions of the skin for microscopy. Although all the clinical signs of acute inflammation were present in each case the only signs proper to the skin itself would appear to be those of redness and possibly heat, due no doubt to a dilatation of the cutaneous vessels. In all the sections examined no microscopical evidence was found of acute inflammation of the skin itself; the inflammatory exudate was confined to the subcutaneous tissues, and there was no invasion of the epidermis by polynuclear or other cells. Cases of acute cellulitis are usually accompanied by a considerable degree of fever and marked constitutional disturbance; - if actual pus formation does not oceur they run a rapid course, tending to recovery. Erysipelas and cellulitis appear to differ only in the effects which an acute inflammation of the skin would give on the one hand, and of the deeper tissues on the other. The epidermis is not a suitable tissue for the development of large abscess cavities within its substance, but the formation of cuticular "blebs" filled with an acute inflammatory exudate is comparable with the larger pockets of pus frequently met with in the subcutaneous tissues in cellulitis.

Lymphangrtis cases. - Five only of these cases were examined and they were clinically chosen as typical instances of the disease. In each case a pure culture (if the additional presence of a diphtheroid bacillus on one occasion be excepted) of the staphylococcus aureus was obtained. The full cultural characters of four of the staphylococci obtained were investigated, but these differ in no way from those of similar organisms isolated from other pathological conditions, with the exception that no clot was produced in milk in any case. Table VIII. shows the cultural properties of the cocci examined.

A portion of the reddened skin was removed on one occasion and no evidence of acute inflammation was found in it. Cases of lymphangitis usually present a longer incubation period and less severe constitutional disturbances than are customary in erysipelas or cellulitis, and in accordance with this they would appear to be usually caused by an organism of different type and less severity. Lymphangitis can, as a rule, only be diagnosed in its early stages, in which the subcutaneous red lines of the inflamed lymphatics are seen to connect the primary lesion with the enlarged, and often suppurating, collections of glands. Staphylococci are particularly liable to spread by the lymphatic circulation and streptococci by

TABLE VIII._Lymphangitis Cases; Staphylococcus Aureus.

\begin{tabular}{|c|c|c|c|c|}
\hline- & Case 9. & Case 16. & Case 19. & Case 37. \\
\hline $\begin{array}{llll}\text { Broth } & \ldots & \ldots & \ldots\end{array}$ & $\begin{array}{l}\text { General } \\
\text { turbidity: }\end{array}$ & $\begin{array}{l}\text { General } \\
\text { turbidity. }\end{array}$ & $\begin{array}{l}\text { General } \\
\text { turbidity. }\end{array}$ & $\begin{array}{c}\text { General } \\
\text { turbidity. }\end{array}$ \\
\hline Agar slant $\ldots . \quad \therefore$ & $\begin{array}{l}\text { Large- } \\
\text { yellow } \\
\text { colonies. }\end{array}$ & $\begin{array}{l}\text { Large } \\
\text { yellow } \\
\text { colonies. }\end{array}$ & $\begin{array}{l}\text { Large } \\
\text { yellow } \\
\text { colonies. }\end{array}$ & $\begin{array}{l}\text { Large } \\
\text { yellow } \\
\text { colonies. }\end{array}$ \\
\hline Jelly slant $\ldots, \ldots$ & $\begin{array}{l}\text { Liquefac- } \\
\text { tion in } 2 \\
\text { hours. }\end{array}$ & $\begin{array}{l}\text { Liquefac- } \\
\text { tion in } 2 \\
\text { hours. }\end{array}$ & $\begin{array}{l}\text { Liquefac- } \\
\text { tion in } 2 \\
\text { hours. }\end{array}$ & $\begin{array}{l}\text { Tiquefac- } \\
\text { tion-in } 2 \\
\text { hours. }\end{array}$ \\
\hline $\begin{array}{l}\text { Neutral red broth } \\
\text { (anaerobically). }\end{array}$ & $\begin{array}{l}\text { Green } \\
\text { fluor- } \\
\text { escence.- }\end{array}$ & $\begin{array}{r}\text { Green } \\
\text { fluor- } \\
\text { eseence. }\end{array}$ & $\begin{array}{l}\text { Green } \\
\text { fluor- } \\
\text { escence: }\end{array}$ & $\begin{array}{l}\text { Green } \\
\text { fluor- } \\
\text { escence.- }\end{array}$ \\
\hline Litmus glucose ... & + & + & + & + \\
\hline Litmus lactose $\ldots$ & + & $+\ldots$ & $+\cdots$ & + \\
\hline Litmus maltose $\ldots$ & $t$ & + & $\ldots+$ & + \\
\hline Litmus mannite... & + . & + & $\ldots+\ldots$ & - \\
\hline Litmus glycerine & + & + & + & + \\
\hline Litmus cane'sugar & + & + & $\cdots-\cdots$ & + \\
\hline Litmus raffinose... & - & - & $\cdots \cdots$ & - \\
\hline Litmus erythrite & - & - & + & + \\
\hline Litmus sorbit & + & - & - & - \\
\hline Litmus salicin $\ldots$ & - & - & + & - \\
\hline Litmus inulin $\quad \ldots$ & - & - & - & - \\
\hline Litmus milk $\quad \ldots$ & $\begin{array}{l}\text { acid, } \\
\text { no clot. }\end{array}$ & $\begin{array}{l}\text { acid, } \\
\text { no clot. }\end{array}$ & $\begin{array}{l}\text { acid, } \\
\text { nó ćlot. } \\
\text {. }\end{array}$ & $\begin{array}{l}\text { acid, } \\
\text { no clot. }\end{array}$ \\
\hline
\end{tabular}

$+=$ acidified $;-=$ no acid production.

direct continuity, so that in infections by the former organism glandular involvement is almost invariable," while in acute streptococcal infections the glands frequently escape. Hence, either glandular enlargement or the presence of a staphylococcus would be in favour of the diagnosis of lymphangitis rather than cellulitis.

Résumé.-The objection that all the cases selected for cultural investigation were not really erysipelas must, ; of course, be met, but the examples chosen were characterised by most of the accepted clinical signs of cutaneous erysipelas - that is to say, in nearly all of them there was a shiny red œdema of the skin.with well-defined edge, and the presence of vesicles on the cutaneous surface, accompanied in most instances by constitutional symptoms of fever, headache, anorexia with initial vomiting, and, not infrequently, shivering or an actual rigor. It was, however, discovered at an early period of this investigation that the certainty of diagnosis of erysipelas rested on three groups of phenomena -namely, such physical signs as have been mentioned above, constitutional disturbance, and the local spread of the erythema with its growing margin, and of these the last appears to be the most constant feature in. streptococcal infections of the skin. Vomiting or shivering may be absent in cases which present the typical skin lesion of erysipelas, while in a few of our cases of cellulitis these severe constitutional disturbances occurred-cases which yielded a growth of a streptococcus but which showed no inflammation of the epidermis. Fever, as a rule, was" much more marked in the typical erysipelas cases than in those of cellulitis, even where a quantity of pus was shut in and required evacuation by the knife, but there were several cases with initial vomiting and a characteristic spreading red rash, in which the temperature was never higher than $100^{\circ}$ F., as taken in the mouth. The conclusion at which we arrived, therefore, was that the most constant and reliable phenomenon on which a diagnosis of erysipelas could be based was the spread of the erythema from a local focus, this spread of infection being characterised by true inflammation of the epidermis with exudation of leucocytes, and not merely a transitory erythema due to vascular dilatation, such as occurs in cellulitis and lymphangitis.

Erysipelas, then, may be caused by a variety of organisms, and if the application of Gordon's tests be allowed as a means of differentiating the various species of streptococci, 
it would appear that a considerable percentage of cases are produced by organisms other than the streptococcus pyogeres. The organisms isolated from the cases of erysipelas vary on lines comparable with those obtained from cases of cellulitis ; nor are any particular cultural properties found in organisms obtained from the one disease and not in those derived from the other. In one instance both local suppuration and typical erysipelas were produced in the same patient by the same streptococcus, an event in accordance with the results obtained in some instances of animal inoculation. The main difference between erysipelas and cellulitis would seem to depend, not upon the viralence of the causative organism, but upon the actual site of the lesion; in erysipelas there is invariably acute inflammation of the epidermis itself; in cellulitis deeper tissues are involved and the epidermis escapes. The period of immunity conferred by an attack of erysipelas is extremely short, and it would appear either that one person is more liable to the infection than another, or that one attack actually predisposes to a second. The course of acute erysipelas would seem at present to be little influenced by serum therapy, and it is possible that a better result might be obtained by the accurate method of obtaining the appropriate serum in each infection, if such a proceeding were practicable. In the few cases of erythemata other than erysipelas examined an organism of the streptococcus class was commonly present in the local wound. In the five cases of lymphangitis examined a typical staphylococcus aureus was obtained in each instance.

In conclusion, we would define erysipelas as an acute inflammation of the epidermis due to the presence of one of the organisms of the streptococcus class, of which the streptococcus pyogenes is the most frequent example. Cellulitis appears to be a strictly comparable inflammation of the cellular tissues, and when the inflammatory processes involve both the epidermis and the cellular tissues the condition of cellulo-cutaneous erysipelas results. Acute lymphangitis would seem to be a less virulent infection due, as a rule, to organisms of the staphylococcus class, with a greater tendency to spread, as its name implies, by the lymphatic system. Erysipelas is not, in the true sense of the term, a specific disease, since it may be produced by a variety of organisms, and these organisms are capable of producing other diseases in other parts of the body.

In the shortness of its incubation period, in the acuteness of its onset-often with marked constitutional disturbances, in its course, in its usual tendency to early and spontaneous cure, and in the nature of the immunity which it confers, erysipelas presents a striking parallel to both acute cellulitis without local suppuration and to acute lobar pneumonia. Nor is it surprising that such similar diseases should all be due, as a rule, to organisms of the same class. the differences in the effect of each disease to the individual being caused by the differences in the localities attacked. It has long been recognised that acute lobar pneumonia may be produced not only by the pneumococcus but also by other similar organisms, such as the streptococcus pyogenes, and that the pneumococcus is capable of effecting an entry and producing disease in other localities than the lung, and we believe that an extension of similar views to the nature of erysipelas constitutes the true etiology of the disease.

We have to thank the members of the staff of St. Thomas's Hospital for permission to make use of their cases.

The Worshipful Company of Plumbers.-The Lord Mayor-elect, Sir John Knill, Bart., was duly sworn into office as Master of the Worshipful Company of Plumbers at the quarterly meeting of the Court at Guildhall on Sept. 30th. Before vacating the chair the late Master, Mr. Adrian Pollock, made an interesting presentation to Mr. Charles Hudson. Past Master and present Renter Warden of the Company, of a copy of a water-colour drawing, showing a view of the old Plumbers' Hall, pulled down to make way for Cannon-street Station. Mr. Hudson is the oldest surviving member of the Court, having taken up his freedom and livery in the old hall in 1854. A committee was appointed to examine the note-books and drawings of the plumber apprentices attending the technical classes whose names appear on the Company's register of indentured apprentices.

\section{A CASE OF SYPHILITIC "REINFECTION" NINE YEARS AFTER, WITH SOME REMARKS ON SYPHILITIC "IMMUNITY" \\ ANI) A NOTE ON TREATMENT.}

BY HENRI DARDENNE, M.D. EDIN., M.R.C.P. LOND, PHYSICIAN TO THE TRENCH HOSPITAL AND THE FRENCH EMBASST IN LONDON.

IN May, 1897, I was consulted by a gentleman for what he called a slight irritation of the penis. He had, he said, never been ill before. On April 10th of the same year he had had connexion, and on May 9th he noticed a slight sore in one of the fossæ of the frænum. On examination I detected a small superficial ulcer in the left fossa. By gently "dipping" the index and thumb and lifting the sore from the subjacent tissues a distinct indurated base could be felt. His inguinal glands were swollen, hard, indolent, and four or five could be felt in each groin. They were characteristic. Hard chancres in that region have two distinct peculiarities: (1) they are, of course, small and crescentic or fissure-like; and (2) the induration at their base has to be looked for in the manner I mentioned above. I at once put him under mercurial treatment and appropriate remedies were applied locally. The chancre healed within three weeks. Six weeks afterwards he developed a typical roseolous rash affecting chiefly the chest, the abdomen, and the inside of both thighs. His throat was congested and mucous patches were to be found on both tonsils and under the tip of the tongue. He consulted Professor Fournier of Paris, who corroborated the diagnosis and also approved of the treatment he was having. The symptoms rapidly subsided and within a few months he was absolutely free from all secondary manifestations. He was very regular in his attendance for over three years. I then lost sight of him until June 18th, 1906, when he again told me that he was very much troubled with another sore of the penis. On examination this proved to be a small circular ulcer about a quarter of an inch in diameter, situated on the dorsal aspect of the coronal fissure. The base was indurated and this distinctly so. The inguinal glands in both groins were characteristic of a syphilitic adenopathy. He had had connexion of a suspicious nature about five weeks previously, and he told me that he had never suffered from any syphilitic "reminders" since I last saw him in 1901. The ulceration healed within 18 days and the glands diminished gradually in size. In July he again developed a copious roseola, and again his buccal mucous membranes became affected. The scalp this time became the seat of a few irritating papules. These secondary symptoms were the exact repetition of what he suffered in 1897. The sarne treatment was again prescribed and this until quite recently.

According to the very great majority of authorities reinfection with the syphilitic virus is possible. Sir Jonathan Hutchinson relates at some length the case of a young surgeon who contracted syphilis in 1860 and who was treated by him with large doses of mercury. In 1865 he again contracted a chancre which indurated and was followed again in due course with a distinct roseola and fresh mucous patches on both tonsils. The same patient, curiously enough, suffered from two attacks of small-pox. Rodet mentions two cases, and in these the interval between the tirst and second infection was four and eight years respectively. Dr. L. Hardie mentions a case, also in a surgeon, who 11 years after the first infection contracted a second chancre which was followed after a few weeks by typical secondary symptoms. All the cases published by Diday are open to caution, for, according to him, the secondary symptoms do not appear after a second infection, but are followed? within a short time by gummas, nodes, and deep serpiginous ulcerations, lesions which are tertiary and may simply be the manifestations of the primary infection. Personally, $\mathbf{r}$ must say, though it has been my lot for the last 16 years to see and to treat, both in my hospital and private practices, several thousand syphilitic patients, that it is my first experience of such a case.

We must be most careful not to confound a true syphilitic reinfection, whose paucity in number's only proves the absolute rarity of such cases, with what Professor Fournier calls 